\title{
Fungal Infections of the Lung
}

\author{
Anke V. Jacobs, MD, and H oward L. Leaf, M D
}

\author{
Address \\ Infectious D iseases Section, N ew York Veterans Affairs Medical C enter, \\ 423 East 23rd Street, N ew York, N Y 10010, USA. \\ Current Infectious Disease Reports 1999, 1:89-98 \\ Current Science Inc. ISSN 1523-3847 \\ Copyright (C) 1999 by Current Science Inc.
}

Fungi, both endemic and opportunistic, continue to be reco gnized as increasingly frequent pulmonary pathogens. Better appreciation of their epidemiology and clinical course, as well as clarification of the roles of the newer triazoles and lipid formulations of amphotericin B in treatment, have occurred within the past few years. Both endemic and opportunistic fungal pulmonary pathogens are reviewed, with emphasis on recent therapeutic advances.

\section{Introduction}

The incidence of the endemic dimorphic fungal infections of the lung ( histoplasmosis, coccioidomycosis, and blastomycosis) has seemingly increased over the past several decades in the United States [1], al though concrete epidemiologic data supporting this perception had been lacking. Some data addressing this issue have recently been published. For example, a report from the Centers for Disease Control and Prevention [2] summarizes trends in incidence rates of coccidioidomycosis in Arizona, and another article sheds some light on the epidemiology of blastomycosis in northeast Tennessee [3].

Of the opportunistic mycoses that may affect the lung, cryptococcosis has been seen at a higher incidence, largely owing to the epidemic of HIV infection. The greater incidence of aspergillosis is due largely to the increasingly prolonged maintenance of critical ill patients, to chemotherapy and radiation therapy for malignancy, to other immunosuppressive drugs, and to the widespread use of antibiotics [4・•].

Each of these most common mycoses is reviewed. Many newer drugs are currently under investigation and are discussed with the individual fungi they affect.

\section{Histoplasmosis}

Approximatel y $90 \%$ of persons infected with $\mathrm{H}$ istoplasma capsulatum are asymptomatic or have an illness so mild that they do not seek medical attention. Depending on the inoculum size and and whether infection results from primary exposure or reexposure in a previously immune host, the incubation period ranges from 3 to 21 days. A heavy inoculum of $\mathrm{H}$. capsulatum can cause acute pulmonary infection in an otherwise heal thy host [5]. The risk of high-inoculum exposure was demonstrated in an immunocompetent patient in Kentucky who was exposed to such an inoculum and developed a severe pulmonary infection [6]. Data from a Mexican study indicate that there may be a genetic risk factor (HLA-22) for pulmonary histoplasmosis [7].

A definitive diagnosis of histoplasmosis requires isolation and identification of the organism by cultures, histologic examination, and antibody and antigen detection. The organism is readily seen in macrophages with the use of either a silver or a periodic acid-Schiff stain. Histoplasma may be isolated from blood, bonemarrow, respiratory tract secretions and other sites, although it may take up to 4 weeks to obtain postive cultures. The best single serologic test is measurement of the Histoplasma polysaccharide antigen (HPA) level [8・•]. This test has a high sensitivity (95\%) and specificity (98\%). Both urine and serum should be tested [9], the better performing diagnostic test is the urinary antigen [10].

Itraconazole has been used successfully in pulmonary, non-life-threatening histoplasmosis, including chronic cavitary pulmonary disease and disseminated non-meningeal histoplasmosis, and for prevention of relapse in patients with AIDS with disseminated histoplasmosis (Table 1) [11]. The recommendation is for $200 \mathrm{mg}$ in a daily oral dose for 9 months. Fluconazole has been compared to itraconazole in recent trials and found to beonly moderately effectivein the treatment of histoplasmosis and should be reserved for patients who cannot tolerate itraconazole, given its intrinsically poorer activity [12]. Patients with life-threatening histoplasmosis (ie, impending respiratory failure) need to be started on amphotericin B. They may benefit from a short course of amphotericin B (total dose, 500-1000 mg) [13], at doses of 0.5 to $1.0 \mathrm{mg} / \mathrm{kg} /$ day IV for 1 week, followed by 0.8 $\mathrm{mg} / \mathrm{kg} /$ day every other day [13]. Some advocate concomitant corticosteroid therapy.

In chronic (cavitary) pulmonary histoplasmosis some success has been achieved with itraconazole 200 mg orally twice a day for 6 to 12 months. In progressive disseminated disease in the immunocompetent host, itraconazole at 400 mg orally twice a day for 6 to 12 months may be considered as first line therapy, if life-threatening disease is not present. Progressive disseminated histoplasmosis is the most common form of the disease among HIV-infected patients. In HIV-infected patients, treatment is not curative and suppressive therapy is needed as relapses are common 


\section{Table 1. Therapeutic guidelines for selected pulmonary mycoses*}

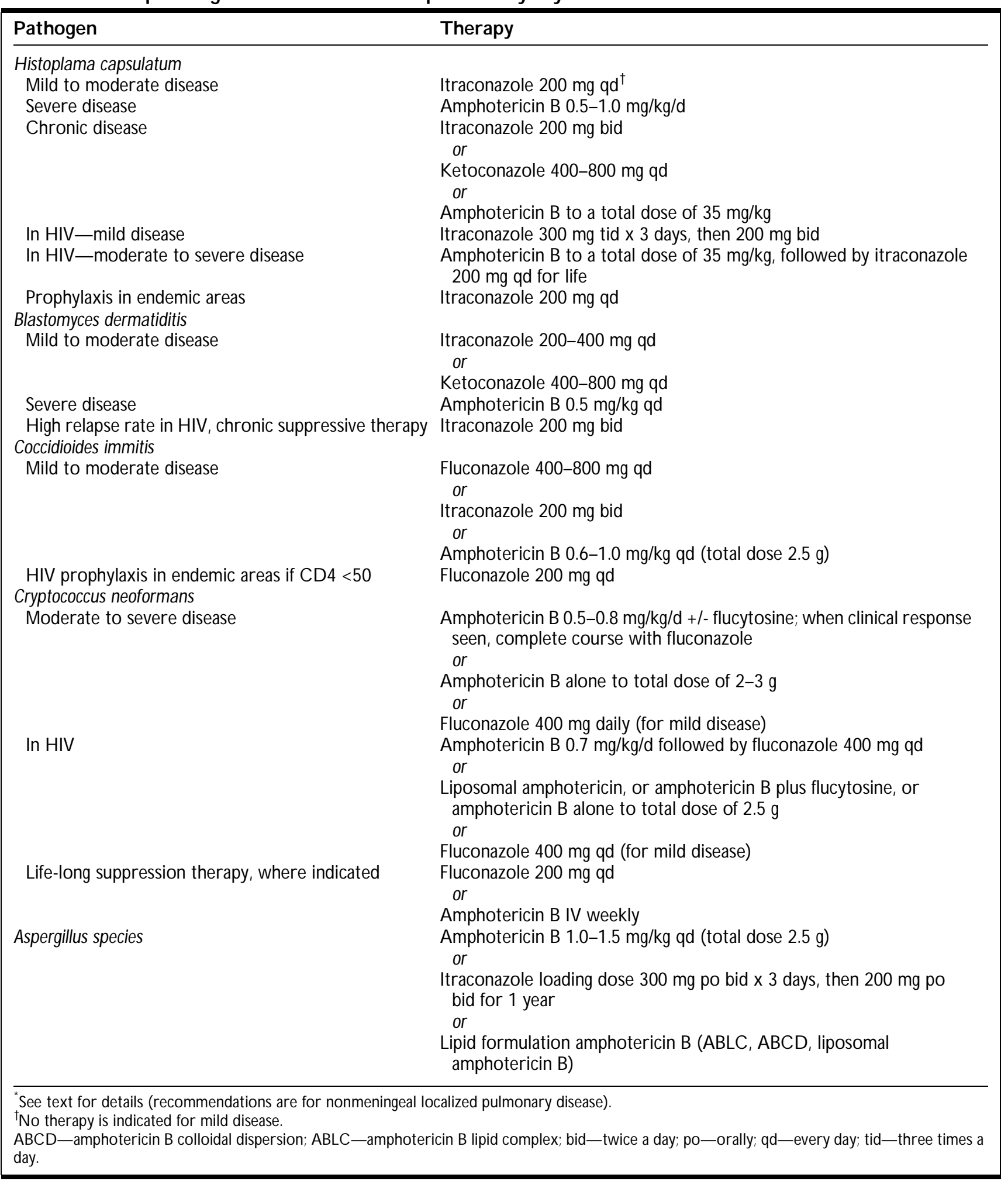

with the cessation of treatment. If, in such patients, disseminated disease is mild, the patient may be treated initially with itraconazole $300 \mathrm{mg}$ orally twice a day for 3 days, followed by $200 \mathrm{mg}$ orally twice a day for 12 weeks [14]. A recent study has also shown fluconazole at doses of
$800 \mathrm{mg}$ oral ly daily over 12 weeks to give a reasonable response [15•]. In moderate to severe disseminated histoplasmosis, amphotericin B should remain the first line of treatment with a total dose of $35 \mathrm{mg} / \mathrm{kg}$ followed by intraconazole $200 \mathrm{mg}$ twice daily indefinitely. With itraconazole 


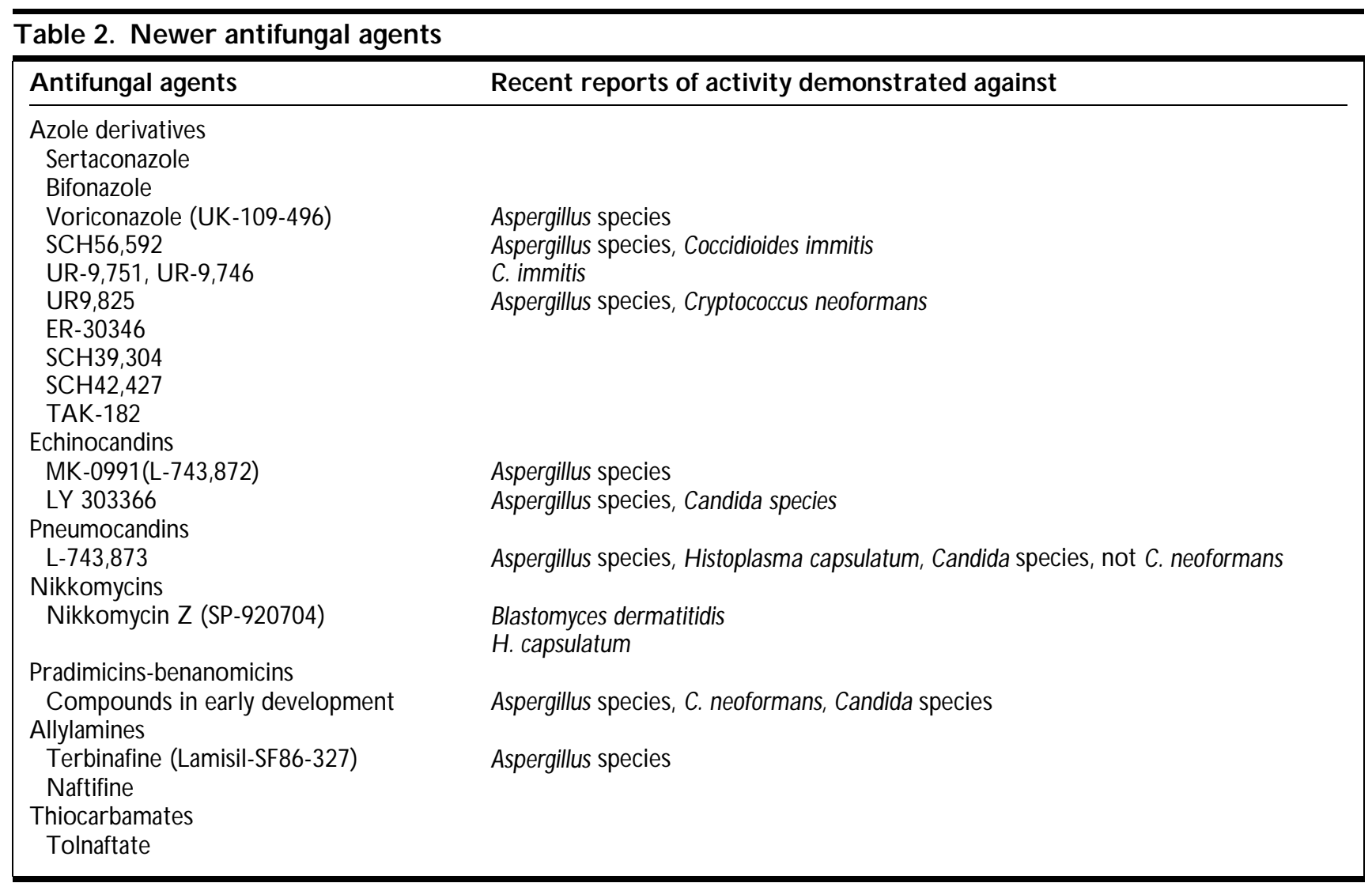

suppressive therapy $200 \mathrm{mg}$ daily fewer than $5 \%$ of patients experience a relapse after an average of 87 weeks of therapy [16•].

MK-991 (L-743,872) has been used in mice to treat for histoplasmosis and was shown to be protective in immunocompetent mice. This suggests that MK-991 may be appropriate for clinical development in histoplasmosis (Table 2) [17].

The patients response to therapy may be foll owed by declining serum and urine $H$. capsulatum var. capsulatum polysaccharide antigen (HPA), which can also be useful in assessing relapse.

The immunocompromised host would greatly benefit from a vacaine Studies focusing on vacaination with recombinant heat shock protein 60 from $H$. capsulatum have shown it to proted mice against pulmonary histoplasmosis [18].

\section{Blastomycosis}

Blastomycosis is a relatively uncommon disease, even in the endemic regions in the United States, such as the upper midwestern, south central, and southeastern areas. The disease is caused by inhalation of airborne spores from Blastomyces dermatitidis, a dimorphic fungus found in soil. The prevalence of the disease is not precisely known because of the lack of an accurate screening test, such as a skin test antigen. A previous study from Wisconsin [19] and a recent study from northeast Tennessee [3] indicate that there has been a significant increase in cases of blastomycosis. In Tennessee the increase in incidence, quadrupling from 1988 to 1995, was found to be coincident with major new construction in the area that disrupted the top soil layer and allowed for aerosolization of spores. Another recent report, however, indicated that in a highly endemic area in Wisconsin, the mean annual incidence of human blastomycosis appears to have remained stable over the past 13 years [20].

The dinical course and symptoms are quite variable [21] and rangefrom asymptomatic, to acute, subacute, or dhronic pulmonary disease, as well as acute lung injury [22], which rarely occurs, but produces an illness with serious morbidity and an estimated $50 \%$ mortality. Acute lung injury, and occasional adult respiratory distress syndrome (ARDS), may occur even in theimmunocompetent host [23].

Although blastomycosis occasionally infects patients with underlying immunosuppression, this is much less frequently seen than in the other endemic mycoses. Nevertheless, it has become an increasingly recognized serious infection in the immunocompromised host in recent years. It has been reported in patients with abnormalities of Tcell function such as those with AIDS, transplant recipients, and patients with long-term glucocorticosteroid use, hematologic malignancy, pregnancy, and other conditions. Clinically, the disease in the immunocompromised patient is potentially much more severe and is characterized by dissemination, frequently affecting the central nervous sys- 
tem. ARDS and miliary pulmonary involvement are common complications encountered in the immunocompromised host, and mortal ity exceeds 30\% [24]. In patients with AIDS, it has been reported in those with CD 4 counts less than 200 cell $\mathrm{s} / \mathrm{mm}^{3}$. Frequently, AIDS patients experience relapses posttreatment.

Because blastomycosis is rel atively uncommon and has such diverse presentations, it is often not considered in the differential diagnosis. A positive culture is considered the gold standard for diagnosis [25]. The organisms may not grow for up to 30 days, however. Occasionally, B. dermatitidis can be identified by direct microscopic examination of the characteristic broad-based budding yeast forms of wet, unstained clinical specimens such as sputum and secre tions, or by special histopathologic stains. B. dermatitidis can also be identified early using DNA probes [25]. At present, no serologic or antigen detection method with adequate sensitivity and specificity or skin test is available

Prior to the development of the azoles, amphotericin B was the drug of choice in severe disease $A$ study comparing in vitro susceptibilities of $B$. dermatitidis to ketoconazole, itraconazole, and fluconazole clearly showed that itraconazole was the most active of this group against $B$. dermatitidis, whereas fl uconazole was least active [26]. In acute disease, the patient may be observed if clinical improve ment is noted, if not, treatment with itraconazole $200 \mathrm{mg}$ po bid for 6 months may be begun. If itraconazole cannot be tolerated, ketoconozole at doses of 400 to $800 \mathrm{mg}$ orally every day may be substituted. Ketoconazole has been used successfully in non-life-threatening di sease, but because of superior efficacy and fewer side effects, itraconzole has largely supplanted ketoconazole for this indication. In acute disease with respi ratory failure, amphotericin B should be the first line of treatment. A daily dose of $0.5 \mathrm{mg} / \mathrm{kg} /$ day to a total dose of greater than 1.5 is recommended [10]. Trials with fluconazole have shown that daily doses of $400 \mathrm{mg}$ to $800 \mathrm{mg}$ for at least 6 months is effective therapy for non-life-threatening blastomycosis [27]. In the normal host, chronic blastomycosis may be initially treated with itraconazole $200 \mathrm{mg}$ oral ly twice a day for 6 months or, al ternatively, ketoconazole 400 to 800 mg orally every day.

In the immunosuppressed patient, treatment may begin with amphotericin $B$ and be changed to itraconazole $200 \mathrm{mg}$ orally twice a day for 6 to 12 months after clinical improvement is noted. In HIV-infected patients, owing to the high relapse rate, especially in those with AIDS, it seems reasonable to administer chronic suppressive therapy with itraconazole $200 \mathrm{mg}$ orally twice a day to prevent relapse [24].

With regard to investigational drugs, the efficacy of nikkomycin Z against experimental pulmonary blastomycosis has been reported. In vitro, nikkomycin $Z$ showed good activity against $B$. dermatiti dis. The efficacies of various treatment durations and doses of nikkomycin $Z$ were compared with those of itraconazole and amphotericin $\mathrm{B}$. The result showed that $100 \%$ survival was achieved with all nikkomycin Z doses. In addition, nikkomycin Z and amphotericin B, but not itraconazole, reduced infection as compared with controls. Nikkomycin Z given orally appeared to be well tolerated and could result in biologic cure[28•].

Besides new antifungal agents, vaccines are being explored. It has been observed that humans infected with B. dermatitidis devel op strong immune responses to the yeast surface adhesin WI-1. A study has looked at the immunogenicity of WI-1 and the ability of anti-WI-1 immune responses to protect against lethal pulmonary infections in mice [29]. The results suggest that admi nistrating WI-1 increases antibody and cell-mediated immune responses, which enhances resistance agai nst pulmonary infections with $B$. dermatitidis in mice. Further investigation of mechanisms of vaccine-induced resistance is indicated.

\section{Coccidioidomycosis}

The incidence of coccidioidomycosis in the southwestern United States has risen sharply over the past decade, mainly because of environmental and demographic changes [30]. A widely reported example of an environmental exposure occurred following the Northridge, California earthquake in 1994, which resulted in a significantly increased risk for developing acute coccidioidomycosis in proximate areas following the event [ $31 \bullet \bullet$ ]. In Arizona between 1990 and 1995, the number of reported cases of coccidioidomycosis increased by $144 \%$. Moreover, persons over the age of 65 years and persons with HIV infection were disproportionately affected. Possible explanations included weather patterns and increasing immigration to the region of a more susceptible older population not previously exposed to coccidioidomycosis and with underlying medical conditions [2].

Cases of coccidioidomycosis have also been reported with increasing frequency from atypical locales, as in a report from Japan, where the patient had worked as a cotton mill worker [32] or as in an imported case in Hungary [33]. Cases of cocci dioidomycosis complicating AIDS are being described more frequently in the endemic areas of the United States. It is the third most commonly reported opportunistic infection in AIDS. In a recent report, one group examined genotypes of Coccidioides immitis and discovered significant differences in the allele frequency between three populations of $C$. immitis studied in California, Arizona, and Texas. This would indicate that the increase seen in coccidioidomycosis in certain areas is due to the particular $\mathrm{C}$. immitis in that region and not to a novel introduced strain [34].

Extrapulmonary complications are uncommon. However, coccidioidomycosis may disseminate and cause disease in skin, bone, and meninges among other sites [35]. Reports of $\mathrm{C}$. immitis causing septic shock have also been reported [36•]. The risk for disseminated cocci dioidomycosis is higher among men, within certain ethnic groups, in 
pregnancy, and in the immunocompromised host. The differences in ethnic groups may be attributed to a gene or genes that increase the susceptibility to infection [35]. Studies in inbred strains of mice have shown that interleukin-10 is consistently associated with susceptibility to infection with C. immitis [37].

Coccidioidomycosis has been observed to be particulary severe in patients with AIDS or organ transplants. A study from UCLA [38] quantified the morbidity and mortality of coccidioidomycosis in liver transplant patients. The median time of onset for infection after transplantation was 8 weeks, and $50 \%$ of patients died. Maintenance therapy is required in the survivors. In a group of HIVinfected patients, overall mortality was 60\% [39].

As most patients with progressive disease have a productive cough with mucopurulent sputum, a rapid direct diagnosis of coccidioidomycosis can often be made by visualization of the organisms in sputum. $C$. immitis grows relatively quickly on appropriate culture media and can be quickly identified by DNA hybridization testing or exoantigen testing. If cultural recovery of the organisms is not successful, bronchoscopy, transbronchial biopsy, throacscopic biopsy, or open-lung biopsy may be needed to make the diagnosis. Cultures of core needle biopsies are, however, insensitive in the detection of specific microorganisms [40]. Serologic testing is extremely valuable in establishing the diagnosis. An IgM antibody to coccidioidin is measured by tube precipitin, immunodiffusion-tubeprecipitin, IgM enzyme-linked immunosorbent assays (ELISAs), or latex agglutination. These tests show positive results early in the course of the illness. IgG is measured by complement-fixation (CF), IgG ELISAs, or immunodiffusion CF. The complement-fixing antibody is quantified and appears only in low titer, if at all, in early disease, but in high titer in most patients with disseminated disease.

The majority of patients with acute primary infection recover without therapy. Patients with severe primary disease should receive therapy, however. Amphotericin B has been the cornerstone of treatment of coccidioidomycosis and is still considered first-line treatment in severe progressive pulmonary disease, as well as in disseminated and severe meningeal disease The azoles, in particular fluconazole and itraconazole, have offered alternatives to the frequently poorly tolerated amphotericin B [35]. A recent report of a Chinese man with disseminated coccidioidomycosis treated with amphotericin B lipid complex (ABLC) represents one clinical success [41]. Further eval uation of therapy with ABLC is needed. Fluconazole at doses of 400 to $800 \mathrm{mg}$ orally every day for a duration of 12 to 18 months can be used to treat acute pulmonary disease as well as extrapulmonary disease and mild-to-moderate meningeal disease $A$ problem encountered with treatment of coccidioidomycosis is the rel atively high relapse rate after apparently successful treatment [42]. All HIV-infected patients with coccidioidomycosis should have treatment continued for life, preferably with fluconazoleor, alternatively, itraconazole Primary pro- phylaxis in HIV patients living in endemic areas with a positive skin test result is not recommended unless the CD4 count is less than 50 cell $\mathrm{s} / \mathrm{mm}^{3}$. These patients should receive either fluconazole $200 \mathrm{mg}$ orally every day or itraconazole $200 \mathrm{mg}$ oral ly every day [43].

Two new azole derivatives, UR-9746 and UR-9751, have been shown to reduce $C$. immitis infection in the spleens, livers, and lungs of treated mice. Neither compound demonstrated any notable toxicity and, on a miligram-per-kilogram of body weight basis, both were at least 10-fold superior to fluconazole in prolonging survival and clearing C. immitis infection [44]. The triazole SCH56592 has been shown in trials against disseminated murine coccidioidomycosis to be superior, at high doses, to fluconazole and itraconazole in reducing colony-forming units in the spleen, liver and lung, and in cures of surviving mice Neither fluconazole or itraconazole was able to effect cure in survivors. Apparently, SCH56592 has potent in vivo activity against C. immitis [45].

Vaccines in animal models are being investigated. A whole-spherule vaccine, which is protective against the lethal dhallenge of laboratory animals with $\mathrm{C}$. immitis, was fractioned and yielded a soluble, subcellular fraction termed the $27 \mathrm{~K}$ vaccine This vaccine, in one report, was able to protect mice against lethal intranasal and intravenous chal lenge with $C$. immitis [46]. Another vaccine under investigation is the recombinant protein, prolinerich antigen (PRA) of C. immitis. Immunized micechallenged intraperitoneally with virulent $C$. immitis had greatly reduced fungal burden in lung and spleen compared with control animals [47].

\section{Aspergillosis}

Aspergillus species are responsible for four types of pulmonary disease, namely allergic bronchopulmonary aspergillosis (ABPA), aspergilloma, chronic necrotizing pulmonary aspergillosis (CNPA), and invasive aspergillosis (Fig. 1) [48]. There has been a substantial increase in the number of cases of invasive aspergillosis found at autopsies. In Frankfurt, Germany, a 14-fold increase in the number of cases between 1978 and 1992 was documented. The reasons for this increase were the advent of AIDS, new intensive chemotherapy for solid tumors and hematologic malignancies, an increase in the number of solid tumor recipients, and immunosuppressive regimens for autoimmune diseases [49••]. Patients with HIV infection have an increased frequency of invasive aspergillosis and their prognosis, despite aggressive antifungal treatment, remains dismal [50]. Cases of invasive aspergillosis in patients with only chronic obstructive pulmonary disease as their underlying defect have been described [51].

The lack of sensitivity of diagnostic procedures delays the time of diagnosis of invasive aspergillosis. Early diagnostic tests are needed, and presumptive antifungal therapy among high-risk patients is mandatory [52]. 


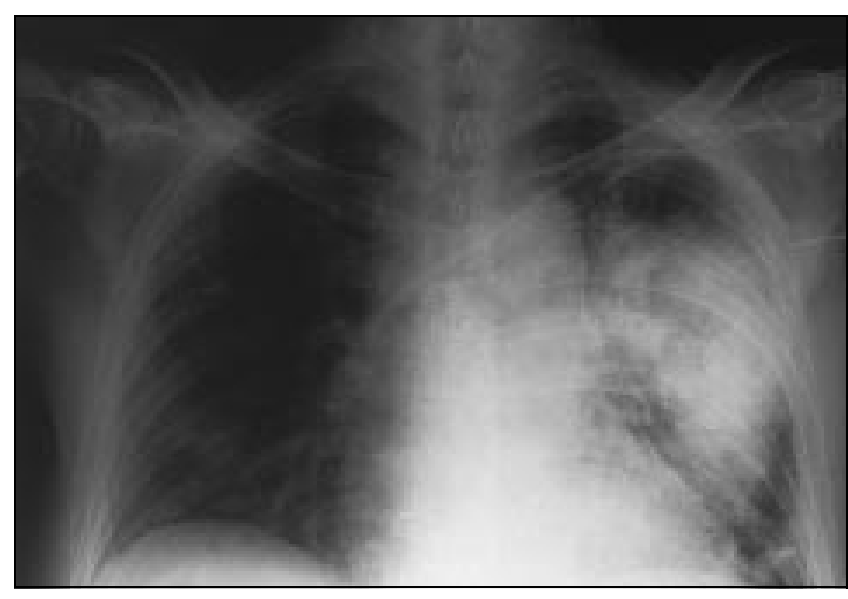

Figure 1. Invasive pulmonary aspergillosis in a patient with multiple myeloma on high-dose corticosteroid therapy.

Demonstration of Aspergillus by both culture and microscopic examination in tissue provides a clear diagnosis. Although repeated isolation of the organism in culture may support the diagnosis, confirmation requires histologic demonstration of tissue invasion by typical septate acute-angle-branching hyphae Serology is of limited value, but recent work to demonstrate antigens appears promising. A recent study compared the latex aggl utination test to a new sandwich ELISA in patients with histologically proven invasive aspergillosis and found that on average the antigen ELISA gave positive results faster and was positive in all patients, as opposed to the latex test, which gave positive results in five of six patients [53].

In the correct clinical setting, CT findings frequently suggest a specific diagnosis [54]. Since 1991, thoracic CT scans at one center weresystematical ly performed in febrile neutropenic patients with pumonary infiltrates. This approach allowed the recognition of a suggestive CT halo sign in $92 \%$ of patients, compared with $13 \%$ before this date, and the mean time to diagnosis of invasive pulmonary aspergill osis was reduced from 7 days to 1.9 days [55].

Although corticosteroids are the mainstay of therapy in ABPA, itraconazole has been used both as monotherapy and as an adjunct to therapy. A recent report described one successful use of itraconazole. Although the patient suffered two relapses, the symptoms subsided without corticosteroid therapy [56].

Medical management of invasive pulmonary aspergillosis is often inadequate in the immunocompromised host. In one series it was shown that surgical resection of invasive pulmonary aspergillosis was able to clear Aspergillus infection in $69 \%$ of the patients and is an effective form of therapy in a properly selected patient population [57]. Intravenous amphotericin B remains the drug of choice for invasive aspergillosis. However, the response remains poor in severely immunocompromised patients. Recommended doses of 1 to $1.5 \mathrm{mg} / \mathrm{kg} /$ day are indicated, to a total dose of $2.5 \mathrm{~g}$. A study from the National Institutes of Allergy and Infectious Disease Mycoses Study Group looked at the use of itraconazole for treatment of invasive aspergillosis and concluded that it is effective in many patients with aspergillosis. A treatment period of several months was required in those patients who responded to obtain an objective improvement [58].

Newer agents are gaining increasing attention. A report of invasive pul monary Aspergillus nidulans infection in a 5-year-old boy with chronic granul omatous disease treated successfully with voriconazole was reported from the Netherlands [59]. A new class of antifungal drugs, the echinocandins and pneumocandins [60], are lipopeptide antifungal agents that inhibit the synthesis of 1,3- $\beta$-Dglucan, a cell wall component found in many pathogenic fungi. LY303366 is an echinocandin with excellent in vitro activity against Aspergillus species. In a neutropenic murine model of invasive aspergillosis, in vivo resistance of Aspergillus fumigatus to amphotericin B was demonstrated, and LY303366 appeared to be effective against amphotericin B-susceptible and -resistant A. fumigatus infections [61]. Comparisons of in vitro activities of the new triazole SCH56592 and the echinocandins MK-0991 (L-743,872) and LY303366 against opportunistic fungi and yeasts have been reported [62]. The results suggest that these new agents have a broad spectrum of activity in vitro. In vivo effectiveness remains to be determined. UR9,825 , a new triazole derivative, has been shown to display good in vitro activity against $A$. fumigatus. It showed good activity in rat systemic infections with Aspergillus after a dose of $1 \mathrm{mg} / \mathrm{kg}$ orally twice a day, but somewhat less than that of amphotericin B [63]. ABLC has been evaluated for its efficacy for invasive fungal infections, including aspergillosis, and results were favorable in patients who cannot tolerate amphotericin B [64]. Two dosages of liposomal amphotericin B for treatment of invasi ve aspergill osis were compared in a European Organization for Research and Treatment of Cancer international multicenter randomized trial [65・•]. The patients were either neutropenic with malignancy or undergoing bone marrow transplantation. The results indicated that the lower dose of $1 \mathrm{mg} / \mathrm{kg} /$ day was just as effective as the $4 \mathrm{mg} / \mathrm{kg} /$ day dose, and no advantages using the higher dose were observed [65••].

Although Aspergillus is infrequently isolated in HIVinfected patients, the associated high mortality rate in documented infection necessitates serious consideration of its clinical significance in those with advanced disease [66]. The treatment of choice is amphotericin $B$ but the mortality rate is greater than $80 \%$ [67]. A study performed at Bell evue Hospital compared pulmonary aspergilloma in the HIV-negative and -positive patient in a retrospective study. It was found that although tuberculosis and sarcoidosis are the most common predisposing disease, Pneumocystis carinii pneumonia in the HIV-infected patient is a risk factor for pulmonary aspergilloma, and that HIV patients with a CD 4 count bel ow $100 \mathrm{cell} / \mathrm{s} / \mathrm{mm}^{3}$ are more likely to have disease progression. It was also seen that the 
HIV-seronegative patients are more likely to develop hemoptysis requiring intervention [68•].

\section{Cryptococcosis}

Lifethreatening infections caused by Cryptococcus neoformans have been increasing over the past 10 years as a result of the AIDS epidemic and the expanded use of immunosuppressive drugs [69・•]. Clinically, the most commonly recognized form of cryptococcosis is meningitis, although a few postmortem studies have indicated that lung and central nervous system disease is seen with equal frequency. AIDS is the predisposing factor in more than $80 \%$ of cryptococcal infections. Primary pulmonary infection may remain mild and asymptomatic even while the fungus is spreading to other organs. Primary pulmonary infections in the normal host are frequently asymptomatic but may regress or progress spontaneously, presenting as a severe pneumonia, or may remain stable for many years. Symptomatic pneumonia is characterized by cough with scant sputum production, sometimes blood-streaked sputum. In HIV patients, fever, cough (at times productive) dyspnea, chest pain, and occasional hemoptysis are typical findings and ARDS may also ensue [70]. On chest radiographs in HIV patients pneumonia frequently presents as diffuse interstitial, al veolar, or nodular pulmonary infiltrates that can be associated with hilar adenopathy and occassional pleural effusions [71]. Focal al veolar consolidation are al so seen, and, in rare instances, cavernous destruction of the lung (cryptococcoma) may be seen [72]. Cryptococcal pneumonia should be considered in the differential diagnosis of P. carinii pneumonia, miliary tuberculosis, or bacterial pneumonia in the HIV patient. Synchronous pulmonary cryptococcosis and histoplasmosis have also been encountered in the immunosuppressed host [73•].

Detection of the organism by culture is required for definite diagnosis. Cryptococcal capsular antigens are shed in body fluids and their detection by the latex cryptococcal agglutinin test in the serum or cerebrospinal fluid is a valuable diagnostic tool [74]. It is less sensitive, however, in nonmeningeal than in meningeal cryptococcosis. Rapid diagnosis by examination of smears with India ink may give support to a presumptive diagnosis. Special histopathologic stains with Mayer's mucicarmine or methenamine silver may reveal the encapsulated single budding yeast. There are al so atypical cytomorphologic appearances of C. neoformans [75], however, which may be confused for other fungal species. DNA-probes for the detection of $C$. neoformans have been studied and may provide means for early diagnosis [76] .

Pulmonary cryptococcosis in the heal thy host may be treated, if treatment is warranted, with fluconazole 200 to $400 \mathrm{mg}$ orally daily, or al ternatively with flucanozole plus flucytosine [77]. In immunosuppressed patients, pulmonary cryptococcosis should be treated initially with amphotericin B with or without flucytosine until stable and then continued on fluconazole 200 mg orally every day for another year. Variations on this basic strategy have been reported [ $78 \cdot \bullet$ ]. Another approach to the primary treatment of cryptococcosis in patients with AIDS would be a relatively high dose of amphotericin $B$ over a short period [79].

The role of lipid preparations is under investigation. Liposomal amphotericin B at $4 \mathrm{mg} / \mathrm{kg}$ resulted in a significantly earlier cerebrospinal fluid culture conversion in meningitis compared with amphotericin $B$ at $0.7 \mathrm{mg} / \mathrm{kg}$, was less nephrotoxic, and had equal clinical efficacy when used for the treatment of primary episode of AIDS-associated cryptococcal meningitis [80]. Lifetime suppression therapy is usual ly with fluconazole $200 \mathrm{mg}$ oral ly every day, although amphotericin B once weekly 0.5 to $1.0 \mathrm{mg} /$ kg IV may be used. Itraconazole may be a suitable al ternative for patients unable to take fluconazole [78••].

Intricate host-organism interactions make the full understanding of the pathogenicity and virulence of $C$. neoformans difficult $[69 \bullet \bullet$. Studies seem to indicate that $C$. neoformans is capable of inducing progression of HIV disease A study from the Netherlands suggests that $C$. neoformans may actually accelerate the course of HIV disease by stimulating the HIV replication through major histocompatibility comple class II-mediated antigen presentation, and that cryptococcal mannoprotein may be one of the responsible components [81]. Another investigation indicated that C. neoformans, as well as Candida albicans, enhance HIV expression in monocytic cells through a tumor necrosis factor- $\alpha$ and NF-кB-dependent mechanism which may further impair host immunity and accelerate the course of HIV disease [82]. In one study it was found that $C$. neoformans is able to induce interleukin- 6 production, which in turn can stimulate replication of HIV in monocytic cells [83]. C. neoformans may be involved in the regulating of $\mathrm{B} 7-1(\mathrm{CD} 80)$ and $\mathrm{B} 7-2(\mathrm{CD} 86)$ costimulatory molecules that may suggest a potential mechanism for the poor inflammatory response observed in C. neoformans infections [84]. Another study looked at the role of exogenous interleukin-10 in the development of immune response agai nst $C$. neoformans. IL-10 is abundantly produced during the progression of AIDS and it was found that the presence of IL-10 in HIV patients may contribute to augment the pathogenic effect of $C$. neoformans [85].

Many agents have been tested for in vitro activity against $C$. neoformans. In one study of such agents, it was found that sertaconazole was statistically more active than bifonazole and terbinafine against $C$. neoformans strains [86]. In another study, the in vitro comparative efficacy of voriconazole and itraconazole against fluconazole-resistant and -sensitive $C$. neoformans were investigated. Voriconazole was more potent than itraconazole for fluconazole-susceptible isolates and as potent as itraconazole for fluconazole-suspectible dose-dependent isolates and for fluconazole-resistant isolates [87]. A study from the United Kingdom investigated the stereosel ective inter- 
action of the azole SCH39304 with the cytochrome P-450 monooxgenase system isolated from $C$. neoformans and found that the SS enantiomer was ableto bind to the P-450 system [88]. A difference in drug susceptibility depending on the serotype of $C$. neoformans has also been seen. Serotype A was less susceptible to fluconazole than serotype D, and both serotypes were highly susceptible to itraconazole [89]. In another study, the effect of chloroquine on the anticryptococcal activity of mononuclear phagocytes was investigated. It was found that chloroquine enhances the activity of mononuclear phagocytes against $\mathrm{C}$. neoformans and is therapeutic in murine models of cryptococcosis. Thus, chloroquine might have clinical utility for the prophylaxis and treatment of human cryptococcosis [90].

Immune-based therapies have been actively investigated as well. The effect of murine IgG1 monoclonal antibody (mAB) $2 \mathrm{H} 1$, which binds to $C$. neoformans glucuronoxylomannan on pulmonary infection in immunocompetent mice was examined. mAB administration prior to infection prolonged survivial without reducing the number of yeast in the body. This study may indicate that antibody administration can produce quanitativeas well as qualitive changes in the inflammatory response to $C$. neoformans [91]. A murinemAB 18B7 to $C$. neoformans polysaccharide is under investigation as a candidate for human therapeutic trials. Administration of this antibody in mice led to a rapid clearance of serum cryptococcal antigen [92]. Granul ocyte col ony-stimulating factor given to HIVinfected subjects improved anticryptococcal acitvity in neutrophils [93].

\section{Conclusions}

Fungi, both endemic and opportunistic, are increasingly important lung pathogens. Triazole antifungal agents have revolutionized therapy in many cases, although for most severe infections amphotericin B as the deoxycholate or as one of the available lipid preparations remains the standard of care Vaccines or other immune-based therapies are largely in early stages of predinical development.

\section{References and Recommended Reading}

Recently published papers of particular interest have been highlighted as:

- Of importance

- Of major importance

1. Catanzaro A: Fungal pneumonias. Curr O pin Pulmon M ed 1997, 3:146-150.

2. Centers for Disease Control and Prevention: Coccidioidomycosis-Arizona, 1990- 1995. M M W R 1996, 45:1069-1073.

3. Vasquez JE, MehtaJB, Agrawal R, et al.: Blastomycosis in northeast Tennessee. Chest 1998, 114:436-443.

4. - Denning DW: Invasive aspergillosis. Clin Infect D is 1998, 26:781-805.

An excellent state-of-the-art dinical article on the entire spectrum on invasive aspergillosis from its history to its treatment and outcome
5. Bradsher RW: Histoplasmosis and blastomycosis. Clin Infect Dis 1996 May, 22 (Suppl 2):S102-S111.

6. Meals LT, McKinney WP: Acute pulmonary histoplasmosis: Progressive pneumonia resulting from high inoculum exposure. Kentucky M ed Assoc 1998, 96:258-260.

7. Tayor ML, Perez-Mejia A, Yamamoto-Furusho JK, Granados]: Immunologic, genetic and social human risk factors associated to histoplasmosis: studies in the State of Guerrero, Mexico. M ycopathologia 1997, 138:137-142.

8. • Sarosi GA, Davies SF: Endemic mycosis complicating human immunodeficiency virus infection [conferences and reviews]. West J M ed 1996, 164:335-340.

A wonderful review of the three major endemic fungi in the United States (histoplasmosis, blastomycosis, coccidioidomycosis). It takes a close look at these pathogenic fungi from their epidemiology all the way to diagnosis and treatment.

9. Shel hamer JH, Gill VJ, Quinn TC, et al.: The laboratory evaluation of opportunistic pulmonary infections. Ann Intern M ed 1996, 124:585-599.

10. Kauffman CA: Role of azoles in antifungal therapy. Clin Infect Dis 1996, 22 (Suppl 2):S148-S153.

11. Wheat J: Histoplasmosis. Experience during outbreaks in Indianapolis and review of the literature. M edicine (Baltimore) 1997 76:339-354.

12. McKinsey DS, Kauffman CA, Pappas PG, et al.: Fluconazole therapy for histoplasmosis. The National Institute of Allergy and Infectious D iseases Mycoses Study Group. Clin Infect D is 1996 23:996-1001.

13. Wheaton J: Histoplasmosis: recognition and treatment [review]. Clin Infect Dis 1994, 19( Suppl 1):S19-S27.

14. Wheat J, Hafner R, Korzun AH, et al.: Itraconazole treatment of disseminated histoplasmosis in patients with the acquired immunodeficiency syndrome. AID S Clinical Trial Group. Am J M ed 1995, 98(4):336-342.

15. Wheat J, MaWhinney S, Hafner R, et al.: Treatment of histoplasmosis with fluconazole in patients with acquired immunodeficiency syndrome. National Institute of Allergy and Infectious D iseases Acquired Immunodeficiency Syndrome Clinical Trials Group and Mycoses Study Group. Am J M ed 1997 103:223-232.

The treatment of histoplasmosis with fluconazole in patients with AIDS is examined in this multicenter, open-labeled, nonrandomized prospective trial. Various dosages were tested and it was concluded that fluconazole at $800 \mathrm{mg}$ daily is moderately effective induction therapy for mild or moderately severe cases of histoplasmosis in the AIDS patient.

16. Hecht FM, Wheat J, Korzun AH, et al.: Itraconazole maintenance treatment for histoplasmosis in AID S: a prospective, multicenter trial. J Acquir Immune D efic Syndr H um Retrovirol 1997, 16:100-107.

This article takes a look at itraconazole $200 \mathrm{mg}$ daily as a preventive measurein therelapse of disseminated histoplasmosis in HIV-patient. It concludes that itraconzole 200 mg daily is effective in preventing relapse and is generally well tolerated.

17. Graybill JR, Najvar LK, Montal bo EM, et al.: Treatment of histoplasmosis with MK-991 (L-743,872). Antimicrob Agents Chemother 1998 42:151-153.

18. Gomez FJ, Allendoerfer R, Deepe GSJr: Vaccination with recombinant heat shock protein 60 from $\mathrm{H}$. capsulatum protects mice against pulmonary histoplasmosis. Infect Immun 1995, 63:2587-2595.

19. Centers for Disease Control and Prevention: BlastomycosisWisconsin, 1986- 1995. M M WR 1996, 45:601-603.

20. Bau mgardner DJ, Brockman K: Epidemiology of human blastomycosis in Vilas County, Wisconsin. II: 1991- 1996. W isconsin M ed J 1998 97:44-47.

21. Davies SF, Sarosi GA: Epidemiological and clinical features of pulmonary blastomycosis [review]. Semin Respir Infect 1997, 12:206-218.

22. Thompson CA, McEachern R, Norman JR: Blastomycosis as an etiology of acute lung injury. South M ed J 1998, 91:861-863. 
23. Mukkamala R, Mehta JB, Myers JW, Cole CP: Pulmonary blastomycosis with acute respiratory failure as predominant clinical feature. South M ed J 1997, 90:847-850.

24. Pappas PG: Blastomycosis in the immunocompromised patient [review]. Semin Respir Infect 1997, 12:243-251.

25. Chao D, Steier KJ, Gomila R: Update and review of blastomycosis [review]. J Am 0 steopath Assoc 1997, 97:525-532.

26. Chapman SW, Rogers PD, Rinaldi MG, Sullivan DC: Susceptibilities of clinical and laboratory isolates of $B$. dermatitidis to ketoconazole, itraconazole, and fluconazole. Antimicrob Agents Chemother 1998 42:978-980.

27. Pappas PG, Bradsher RW, Kauffman CA, et al.: Treatment of blastomycosis with higher doses of fluconazole. The National Institute of Allergy and Infectious D iseases Mycoses Study Group. Clin Infect D is 1997, 25:200-205.

28. Clemons KV, Stevens DA: Efficacy of nikkomycin $Z$ against experimental pulmonary blastomycosis. Antimicrob Agents Chemoth 1997, 41:2026-2028.

Nikkomycin Z is compared at various doses and treatment durations to amphotericin $B$ and itraconazole in a murine model of pulmonary blastomycosis. The results indicated that nikkomycin $\mathrm{Z}$ is well tolerated, and has good activity against blastomycosis.

29. Wuthrich $M$, Chang WL, Klein BS: Immunogenicity and protective efficacy of the WI-1 adhesin of B. dermatitidis. Infect Immun 1998, 66:5443-5449.

30. Vaz A, Pineda-Roman M, Thomas AR, Carlson RW: Coccidioidomycosis: an update [review]. H osp Pract 1998, 3:105-120.

31. • Schneider E, Hajjeh RA, Spiegel RA, et al.:Coccidioidomycosis outbreak following the Northridge, Calif, earthquake. JAM A. 1997, 277:904-908.

This study demonstrates a direct correlation between the disruption of soil, as seen in this Californian earthquake, and an increase in infections caused by $C$. immitis.

32. Ogiso A, Ito M, Koyama M, et al.: Pulmonary coccidioidomycosis in Japan: case report and review. Clin Infect D is 1997, 25:1260-1261.

33. Zalatnai A, Zala J, Sandor G: Coccidioidomycosis in H ungary: the first import case. Pathol O ncol Res 1998, 4:147-151.

34. Burt A, Dechairo BM, Koenig GL, et al.: Molecular markers reveal differentiation among isolates of Coccidioides immitis from California, Arizona and Texas. M olec Ecol 1997, 6:781786.

35. Kirkland TN, Fierer J: Coccidioidomycosis: a reemerging infectious disease [synopses]. Emerg Infect D is 1996, 2:192-199.

36. Arsura EL, Bellinghausen PL, KilgoreWB, et al.: Septic shock in coccidioidomycosis. Crit Care M ed 1998, 26:62-65.

This article looks at the clinical and laboratory paramenters of septic shock in patients infected with $\mathrm{C}$. immitis and offers guidelines for earlier diagnosis of this syndrome

37. Fierer J, Walls L, Eckmann L, et al.: Importance of interleukin10 in genetic susceptibility of mice to Coccidioides immitis. Infect Immun 1998, 66:4397-4402.

38. Holt CD, Winston DJ, Kubak B, et al.: Coccidioidomycosis in liver transplant patients. Clin Infect D is 1997, 24:216-221.

39. Singh VR, Smith DK, Lawrence J, et al.: Coccidioidomycosis in patients infected with human immunodeficiency virus: review of 91 cases at a single institution. Clin Infect D is 1996, 23:563-568.

40. Chitkara YK: Evaluation of cultures of percutaneous core needle biopsy specimens in the diagnosis of pulmonary nodules. Am J Clin Pathol 1997, 107:224-228.

41. Koehler AP, Cheng AF, Chu KC, et al.: Successful treatment of disseminated coccidioidomycosis with amphotericin B lipid complex. J Infection 1998, 36:113-115.

42. Dewsnup DH, Gal giani JN, Graybill JR, et al.: Is it ever safe to stop azole treatment for Coccidioides immitis meningitits? Ann Intern M ed 1996, 124:305-310.

43. Ampel NM, Dols CL, Gal giani JN: Coccidioidomycosis during human immunodeficiency virus infection: results of a prospective study in a coccidioidal area. Am J M ed 1993, 94:235240.
44. Clemons KV, Stevens DA: Efficacies of two novel azole derivatives each containing a morpholine ring, UR-9746 and UR9751, against systemic murine coccidioidomycosis. Antimicrob Agents Chemother 1997, 41:200-203.

45. LutZJE, Clemons KV, Aristizabal BH, StevensDA: Activity of the triazole SCH 56592 against disseminated murine coccidioidomycosis. Antimicrob Agents Chemother 1997, 41:1558-1561.

46. Zimmermann CR, Johnson SM, Martens GW, et al.: Protection against lethal murine coccidioidomycosis by a soluble vaccine from spherules. Infect Immun 1998, 66:2342-2345.

47. Kirkland TN, Finley F, Orsborn KI, Galgiani JN: Evaluation of the proline-rich antigen of Coccidioides immitis as a vaccine candidate in mice. Infect Immun 1998, 66:3519-3522.

48. Broderick LS, Conces DJ, Tarver RD, et al.: Pulmonary aspergillosis: a spectrum of disease [review]. Crit Rev Diagn Imag 1996, 37:491-531.

49. • Denning DW: Invasive Aspergillosis. Clin Infect D is 1998, 26:781-805.

An excellent state-of-the-art clinical article on the entire spectrum of invasive aspergillosis from its history to its treatment and prognosis.

50. Mylonakis E, Mileno MD, Flanigan T, et al.: Pulmonary invasive aspergillosis in patients infected with the human immunodeficiency virus: report of two cases. H eart Lung 1998, 27:63-66.

51. Rello J, Esandi M, Mariscal D, et al.: Invasive pulmonary aspergillosis in patients with chronic obstructive pulmonary disease: report of eight cases and review-brief reports. Clin Infect D is 1998, 26:1473-1475.

52. Kaiser L, Huguenin T, Lew PD, et al.: Invasive aspergillosis: clinical features of 35 proven cases at a single institution. M edicine 1998, 77:188-194.

53. Herrmann J, Gugel A, Freidank $H$, et al.: Aspergillus antigen detection: comparison of a new sandwich ELISA with the latex agglutination test in patients with histologicly proven invasive aspergillose. M ycoses 1998, 41(Suppl 1):83-85.

54. Logan PM, Muller NL: High-resolution computed tomography and pathologic findings in pulmonary aspergillosis: a pictorial assay. Can Assoc Radiol J 1996, 47:444-452.

55. Caillot D, Casasnovas O, Bernard A, et al.: Improved management of invasive pulmonary aspergillosis in neutropenic patients using early thoracic computed tomographic scan and surgery. J Clin O ncol 1997, 15:139-147.

56. Nikaido $Y$, Nagata N, Yamamoto T, et al.: A case of allergic bronchopulmonary aspergillosis successfully treated with itraconazole. Respir M ed 1998, 92:118-124.

57. Salerno CT, Ouyang DW, Pederson TS, et al.: Surgical therapy for pulmonary aspergillosis in immunocompromised patients. Ann Thorac Surg 1998, 65:1415-1419.

58. Stevens DA, LeeJY: Analysis of compassionate use of itraconazole therapy for invasive aspergillosis by the NIAID Mycoses Study Group criteria. Arch Intern M ed 1997, 157:1857-1862.

59. van Ôt Hek LG, Verweij PE, Weemaes CM, et al.: Successful treatment with voriconazole of invasive aspergillosis in chronic granulomatous disease. Am J Respir C rit Care M ed 1998, 157:1694-1696.

60. Denning DW: Echinocandins and pneumocandins- a new antifungal class with a novel mode of action. J Antimicrob Chemother 1997, 40:611-614.

61. Verweij PE, Oakley KL, Morrissey J, et al.: Efficacy of LY303366 against amphotericin B susceptible and resistant Aspergillus fumigatus in a murine model of invasive aspergillosis. Antimicrob Agents Chemother 1998, 42:873-878.

62. Espinel-Ingroff A: Comparison of in vitro activities of the new triazole SCH 56592 and the echinocandins MK-0991 (L$\mathbf{7 4 3 , 8 7 2}$ ) and LY303366 against opportunistic filamentous and dimorphic fungi and yeasts. J Clin M icrobiol 1998, 36:2950-2956.

63. Bartroli J, Turmo E, Alguero M, et al.: UR-9,825: a new triazole derivative with potent, broad-spectrum antifungal activity. In Program and Abstracts of the 37th Interscience Conference on Antimicrobial Agents and Chemotherapy. Washington, DC: American Society for Microbiology; 1997:125. 
64. Walsh TJ, Hiemenz JW, Seibel NL, et al.: Amphotericin B lipid complex for invasive fungal infections: analysis of safety and efficacy in 556 cases. Clin Infect D is 1998, 26:1383-1396.

65. • Ellis M, Spence D, de Pauw B, et al.: An EORTC international multicenter randomized trial (EORTC number 19923) comparing two dosages of liposomal amphotericin B for treatment of invasive aspergilosis. Clin Infect D is 1998, 27:14061412.

This is the first completed prospective randomized clinical efficacy trial of antifungals in the treatment of invasive aspergillosis. This study compares the dinical efficacy of two doses of liposomal amphotericin B in immunosuppressed patients.

66. Wallace JM, Lim R, Browdy BL, et al.: Risk factors and outcomes associated with identification of Aspergillus in respiratory specimens from persons with HIV disease. Pulmonary complications of HIV infection study group. Chest 1998, 114:131-137.

67. - Mylonakis E, Barlam TF, Flanigan T, Rich JD: Pulmonary aspergillosis and invasive disease in AID S: review of $\mathbf{3 4 2}$ cases. Chest 1998, 114:251-262.

Aspergillosis is still an uncommon infection in the HIV population. However, it is frequently fatal. This article reviews the typical symptoms, predisposing factors and diagnostic approaches.

68. - Addrizzo-Harris DJ, Harkin TJ, McGuinness G, et al.: Pulmonary aspergilloma and AIDS: a comparison of HIV-infected and HIV-negative individuals. Chest 1997, 111:612-618.

Aspergilloma has been reportedly relatively rarely in HIV disease. The impact of HIV on pulmonary aspergilloma is investigated. Risk factors are discussed.

69. • Buchanan KL, Murphy JW: What makes Crytpococcus neoformans a pathogen? Emerg Infect D is Synop 1998, 4:71-80.

$A$ very in depth look at the pathogenicity and virulence of $C$. neoformans and the realization that many questions still need to be answered.

70. Vinergarwala F, Graviss EA, Lacke CE, et al.: Acute respiratory failure associated with cryptococcosis in patients with AIDS: analysisof predictive factors. Clin Infect D is 1998, 27:12311237.

71. Miller KD, Mican JA, Davey RT: Asymptomatic solitary pulmonary nodules due to Cryptococcus neoformas in patients infected with human immunodeficiency virus. Clin Infect D is 1996, 23:810-812.

72. Schubert S, Lebeau A, Zell R, Goebel F: Cavitary cryptococcoma of the lungs and meningitis by Cryptococcus neoformans in a patient with AIDS. Eur J M ed Res 1997, 2(4):173-176.

73. - Ramirez-Ortiz R, Rodriguez J, Soto Z, et al.: Synchronous pulmonary cryptococcosis and histoplasmosis. South M ed J 1997, 90:729-732.

The first reported case of concominant infection by Cryptococcus and H istoplasma.

74. Feldmesser M, Harris C, Reichberg S, et al.: Serum cryptococcal antigen in patients with AIDS [editorial]. Clin Infect D is 1996, 23:827-830.

75. Williamson JD, Silverman JF, Mallak CT, Christie JD: Atypical cytomorphology appearance of Cryptococcus neoformans: a report of five cases. Acta Cytologica 1996, 40:363-370.

76. Wu J, Liao W, Chai J: Isolation of specific DNA probes for detection of C rytococcus neoformans. M ycoses 1997, 40:385389.

77. Yamamoto Y, Maesaki S, Kakeya H, et al.: Combination therapy with fluconazole and flucytosine for pulmonary cryptococcosis. Chemotherapy 1997, 43:436-441.

78. $\cdots$ van der Horst CM, Saag MS, Cloud GA, et al.: Treatment of cryptococcal meningitis associated with the acquired immunodeficiency syndrome. National Institute of Allergy and Infectious Disease Mycoses Study Group and AIDS Clinical Trials Group. N Engl J M ed 1997, 337:1557-1558.

The most common presentation of cryptococcosis in the HIV patient is meningitis. The cornerstone of treatment has been amphotericin $B$ alone This study compares amphotericin B with and without flucytosine and looks at consolidation therapy.
79. de Lalla F, Pellizzer G, Vaglia A, et al.: Amphotericin B as primary herapy for C ryptococcus in patients with AIDS: reliability of relatively high doses administred over a relatively short period. Clin Infect D is 1995, 20:263-266.

80. Leenders AC, Reiss P, Portegies P, et al.: Liposomal amphotericin B (AmBisome) compared with amphotericin B both followed by oral fluconazole in the treatment of AIDSassociated cryptococcal meningitis. AID S 1997, 11:14631471.

81. Orendi JM, Verheul AF, De Vos NM, et al.: Mannoproteins of Cryptococcus neoformans induce proliferative response in human peripheral blood mononuclear cells (PBMC) and enhance HIV-1 replication. Clinic Exper Immunol 1997, 107:293-299.

82. Harrison TS, Nong S, Levitz SM: Induction of human immunodeficiency virus type 1 expression in monocytic cells by Cryptococcus neoformans and Candida albicans. J Infect D is 1997, 176:485-491.

83. Delfino D, Cianci L, Lupis E, et al.: Interleukin-6 production by human monocytes stimulated with Cryptococcus neoformans components. Infect Immun 1997, 65:2454-2456.

84. Vecchiarelli A, Monari $C$, Retini $C$, et al.: Cryptococcus neoformans differently regulates B7-1 (CD 80) and B7-2 (CD 86) expression on human monocytes. Eur J Immunol 1998, 28:114-121.

85. Monari C, Retini C, Palazzetti B, et al.: Regulatory role of exog enous IL-10 in the development of immune response versus Cryptococcus neoformans. Clin Exp Immunol 1997, 109:242-247.

86. Carillo-Munoz AJ, Tur-Tur C: Comparative study of antifungal activity of sertaconazole, terbinafine, and bifonazole against clinical isolates of $\mathrm{C}$ andida spp., Cryptococcus neoformans and dermatophytes. Chemotherapy 1997, 43:387-392.

87. Nguyen MH, Yu CY: In vitro comparative efficacy of voriconazole and itraconazole against fluconazole-susceptible and resistant Cryptococcus neoformans isolates. Antimicrob Agents Chemother 1998, 42:471-472.

88. Lamb DC, Baldwin BC, Kwon-Chung KJ, et al.: Stereoselective interaction of the azole antifungal agent SCH 39304 with the cytochrome P-450 monooxygenase system isolated from Cryptococcus neoformans. Antimicrob Agents Chemother 1997, 41:1465-1467.

89. Tortorano AM, Viviani MA, Rigoni AL, et al.: Prevalence of serotype $D$ in Cryptococcus neoformans isolates from HIV positive and HIV negative patients in Italy. M ycoses 1997, 40:297302.

90. Levtitz SM, Harrison TS, Tabuni A, Liu X: Chloroquine induces human mononuclear phagocytes to inhibit and kill Cryptococcus neoformans by a mechanism independent of iron deprivation. J Clin Invest 1997, 100:1640-1646.

91. Feldmesser M, Kress Y, Casadevall A: Effect of antibody to capsular polysaccharide on eosinophilic pneumonia in murine infection with Cryptococcus neoformans. J Infect D is 1998, 177:1639-1646.

92. Casadevall A, Cleare W, Feldmesser M, et al.: Characterization of a murine monoclonal antibody to Cryptococcus neoformans polysaccharide that is a candidate for human therapeutic studies. Antimicrob Agents Chemother 1998, 42:1437-1446.

93. Coffey MJ, Phare SM, George S, et al.: Granulocyte colonystimulating factor administration to HIV-infected subjects augments reduced leukotriene synthesis and anticryptococcal activitiy in neutrophils. J Clin Invest 1998, 102:663-670. 